New Book Received*

\title{
The Green Leap: A Primer for Conserving Biodiversity in Subdivision Development. By Mark E. Hostetler, University of California Press, 2012; 205 pages. Price: US\$ 26.95 / £ 18.95 ISBN 978-0-520-27111-1
}

Received: 16 April 2012 / Published: 20 April 2012

The following paragraphs are reproduced from the website of the publisher [1].

Written for anyone interested in green development-including policy makers, architects, developers, builders, and homeowners - this practical guide focuses on the central question of how to conserve biodiversity in neighborhoods and to minimize development impacts on surrounding habitats. The Green Leap specifically helps move green development beyond the design stage by thoroughly addressing construction and post-construction issues.

Incorporating many real-world examples, Mark Hostetler explains key conservation concepts and techniques, with specific advice for a wide variety of stakeholders that are interested in creating and maintaining green developments. He outlines the key players and principles needed to establish biodiverse communities and illustrates eight key design and management strategies. The Green Leap not only offers essential information for constructing new developments but also helps existing communities retrofit homes, yards, and neighborhoods to better serve both people and nature.

Table of Contents:

List of Boxed Texts

Preface and Acknowledgments

Part One. Key Principles and Players

1. Why Build Biodiverse Communities?

2. Urban Decision Makers

Part Two. The Devil Is in the Details

3. Tree Protection and Natural Area Preservation Strategies

4. Improving Community Engagement and Understanding

5. Landscaping and Individual Lots

6. Trails, Sidewalks, and Common Areas

7. Irrigation and Stormwater Treatment

8. Wildlife-Friendly Transportation Systems 
9. Environmental Covenants, Conditions, and Restrictions

10. Certifying Green Communities

In Summary

Notes

Index

* Editor's Note: The brief summary and the contents of the books are reported as provided by the authors or the publishers. Authors and publishers are encouraged to send review copies of their recent books of potential interest to readers of Diversity to the Publisher (Dr. Shu-Kun Lin, Molecular Diversity Preservation International (MDPI), Kandererstrasse 25, CH - 4057 Basel, Switzerland. Tel. +41 6168377 34; Fax: +41 6130289 18; E-mail: lin@mdpi.org). Some books will be offered to the scholarly community for the purpose of preparing full-length reviews.

\section{Note}

1. The website for this book is http://www.ucpress.edu/book.php?isbn=9780520271111.

(C) 2012 by the authors; licensee MDPI, Basel, Switzerland. This article is an open access article distributed under the terms and conditions of the Creative Commons Attribution license (http://creativecommons.org/licenses/by/3.0/). 